\title{
Exploring the sensing behavior in the detection of nitroaromatics using coordination complexes based on 4,4'-(1,3-phenylenedioxy)-dianiline ligand
}

A R T I C L E I N F O

\section{Keywords:}

Coordination polymers

Nitroaromatic sensing

Solid-state chemistry

Coordination bonds

$\mathrm{X}$-ray diffraction

\begin{abstract}
A B S T R A C T
The aromatic ligand 4,4'-(1,3-phenylenedioxy)-dianiline (L), has been used to explore its coordination chemistry behaviour and nitroaromatic sensing ability by crystallizing it with a variety of transition metals. The supramolecular structures $\left[\mathrm{CuCl}_{2}(\mathrm{~L})\right](1),\left[\mathrm{Mn}\left(\mathrm{H}_{2} \mathrm{O}\right)_{2} \mathrm{Cl}_{2}(\mathrm{~L})_{2}\right](2),\left[\mathrm{Ni}\left(\mathrm{H}_{2} \mathrm{O}\right)_{2}(\mathrm{~L})_{2}\right] \mathrm{Cl}_{2}(3)$ and $\left[\mathrm{Co}\left(\mathrm{H}_{2} \mathrm{O}\right)_{2}(\mathrm{~L})_{2}\right] \mathrm{Cl}_{2}(4)$ have been characterized by single crystal X-ray diffraction (SC-XRD) and X-ray powder diffraction (XRPD) analysis. While 1 and $\mathbf{2}$ do not form polymeric structures but discrete (OD) arrays, $\mathbf{3}$ and $\mathbf{4}$ resulted in extended isostructural 2D coordination polymers. The solid-state fluorescence properties of the reported crystals have been investigated. Interestingly, coordination polymers 3 and 4 showed a better solid-state fluorescence emission compared to that of complexes $\mathbf{1}$ and $\mathbf{2}$. Coordination polymer $\mathbf{3}$ has been successfully used as a sensor for the detection of trace amounts of nitrobenzene, 2-nitrotoluene and 3-nitrotoluene with a high quenching efficiency of $96 \%$ for 3-nitrotoluene. The quenching efficiency of 3 is better than that of the free ligand L. The polymeric nature of $\mathbf{3}$ is maintained after the sensing experiment and thus can be used in a recyclable manner. Due to the fact that $\mathbf{3}$ is a nonporous and its structure does not change in the presence of the quenchers, the quenching effect occurs in the surface of the solids when is in a suspension.
\end{abstract}

\section{Introduction}

The crystal engineering approach to design functional materials is a powerful method to generate new advanced compounds displaying properties in relevant technological areas [1]. For instance the self-assembly of organic molecules with transition metals can be used (most often using solvent molecules as templating agents) to form hybrid metal organic solids with void spaces filled with solvent in their structures (i.e., porosity) [2]. The porous nature of the metal-organic structures can be exploited, for instance as filters, for the adsorption of toxic molecules in the gas or liquid state (i.e., pollutants) [3]. In this regard, metal organic frameworks (MOFs) and coordination polymers (CPs) have shown to be promising candidates as highly functional materials to treat pollution problems $[1 \mathrm{~b}, 4]$.

The inclusion of photoactive organic molecules in the crystalline lattice of the coordination polymers has been exploited to obtain functional materials showing photoluminescent properties such as fluorescence emission [5]. In fact, the photoactive behaviour of the framework structures can be used for example, for the sensing of nitroaromatic compounds [6]. Another class of metal-organic materials that can be used for the sensing of nitroaromatics are the so-called second sphere coordination adducts in which the metal ions and organic ligands are self-assembled via electrostatic interactions, mainly charge assisted hydrogen bonds [7].

Usually, organic ligands containing aromatic groups are good candidates to act as a source of luminescence due to the presence of electron-rich aromatic groups. Organic molecules containing pyridine groups have been widely used and shown to produce great variety of networks with functional applications [8]. However aromatic diamine ligands have been less employed due to its poor stability and donor ability of the amine groups towards the metal centres [9].

Recently, we have demonstrated that by using 4,4'-methylenedianiline which is a flexible molecule due to the single bond between the aromatic rings ( $\mathrm{V}$-shape), in combination with transition metal based $\left[\mathrm{MX}_{4}\right]^{2-}$ anions $(\mathrm{M}=\mathrm{Cu}$ or $\mathrm{Cd}, \mathrm{X}=\mathrm{Cl}$ or $\mathrm{Br})$ it is possible to construct second sphere coordination adducts containing 1D channels via charge assisted hydrogen bonds [10]. Using the same approach, the unexplored optoelectronically active organic building block, 4,4'-(1,1'-biphenyl-

\footnotetext{
* Corresponding authors at: College of Chemistry, Liaoning University, Shenyang 110036, China (F. Guo); Dipartimento di Chimica, Materiali e Ingegneria Chimica. “Giulio Natta”, Politecnico di Milano, Via L. Mancinelli 7, 20131 Milan, Italy (J. Martí-Rujas).

E-mail addresses: javier.marti@polimi.it (J. Martí-Rujas), fguo@lnu.edu.cn (F. Guo).
} 


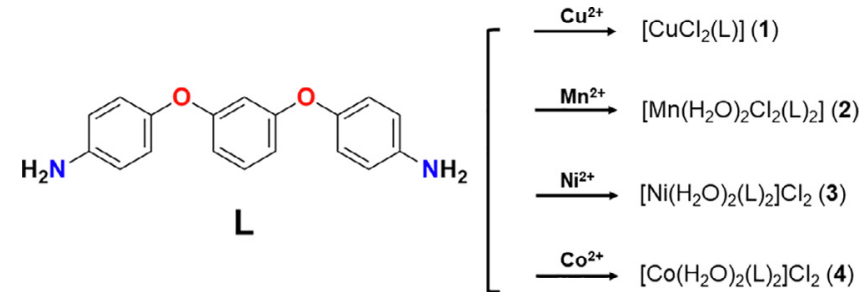

Fig. 1. Ligand $\mathbf{L}$ used to prepare coordination complexes and polymers 1-4 described in this work.

4,4'-diyldioxy)di-aniline, has been recently used to form a photoactive 2D perovskite by using second sphere coordination interactions in the presence of $\mathrm{Cu}$ metal which has shown to emit in the UV/blue region [11].

The aromatic diamine ligand 4,4'-(1,3-phenylenedioxy)-dianiline (L) (Fig. 1) is a flexible molecule with a higher $\pi$-electron-rich ability than 4,4'-methylenedianiline and therefore, can be used to self-assemble with transition metals to form metal-organic materials. The potential twisted conformations owing to the rotation along the $\mathrm{C}-\mathrm{O}-\mathrm{C}$ bond between the benzene and aniline ring makes $\mathbf{L}$ a good candidate to create flexible frameworks structures with new topologies. To the best of our knowledge, $\mathbf{L}$ has been used for the synthesis of polymer materials by involving the reaction of the $\mathrm{NH}_{2}$ group, such as polybenzoxazine and polydimethylsiloxane crosslinked polymer materials [12] and poly(amide-imide)s [13]. However, direct coordination with metal ions has been rarely reported using $\mathbf{L}$.

Here we report nitroaromatic sensing ability of four metal-organic coordination compounds (1-4) self-assembled using metal chloride salts and ligand $\mathbf{L}$, namely $\left[\mathrm{CuCl}_{2}(\mathrm{~L})\right](1),\left[\mathrm{Mn}\left(\mathrm{H}_{2} \mathrm{O}\right)_{2} \mathrm{Cl}_{2}(\mathrm{~L})_{2}\right](2)$, $[\mathrm{Ni}$ $\left.\left(\mathrm{H}_{2} \mathrm{O}\right)_{2}(\mathrm{~L})_{2}\right] \mathrm{Cl}_{2}$ (3) and $\left[\mathrm{Co}\left(\mathrm{H}_{2} \mathrm{O}\right)_{2}(\mathrm{~L})_{2}\right] \mathrm{Cl}_{2}$ (4). The structures of the coordination compounds 1-4 have been characterized by single crystal X-ray diffraction and powder X-ray diffraction. The solid-state photoluminescent (PL) behavior of the four hybrid materials has been monitored and the coordination polymer $\mathbf{3}$ was used for the detection of trace amounts of nitrobenzene derivatives showing high quenching efficiency. The nonporous nature and stability of the coordination polymer 3 in the suspensions suggests that the quenching effect occurs at the surface of the solids.

\section{Results and discussion}

Ligand $\mathbf{L}$ was reacted with $\mathrm{MCl}_{2} \cdot \mathrm{nH}_{2} \mathrm{O}(\mathrm{M}=\mathrm{Cu}$, Co, Mn, Ni) using different metal to ligand ratios. Large single crystals of 1 were prepared by the triple layering method whereas single crystals of 2-4 were obtained via slow vapour diffusion of dichloromethane or ethyl ether into an ethanol solution of microcrystalline 2-4 (See ESI). All single crystal species are stable in contact with air once isolated.

The four complexes were structurally characterized by SC-XRD (ESI) and the phase purity of the crystalline materials was confirmed by comparing the experimental and simulated XRPD diffraction patterns. The hybrid metal-organic materials 1-4 can also be readily obtained by liquid-assisted grinding (LAG) [14], as seen in the XRPD patterns (ESI). It is worth mentioning that the grinding method is much simpler helping to reduce the solvent waste which is usually employed using solution procedures (i.e., tedious synthetic and crystallization procedures). This aspect is crucial for the applications in nitroaromatic sensing in which suspensions of microcrystalline materials are used.

\section{Description of the structures}

\section{1. $\left[\mathrm{CuCl}_{2}(L)\right](1)$.}

X-ray crystallography reveals that $\mathbf{1}$ crystallizes in orthorhombic Pnma space group. The ligand in $\mathbf{1}$ undergoes a large twist compared to

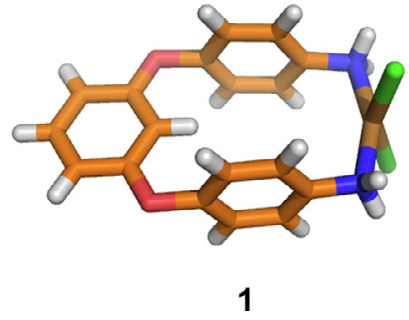

Fig. 2. The single crystal X-ray structure of 1 . Color code: carbon: orange; nitrogen: blue; oxygen: red; chloride: green; copper: brown; hydrogen: white.

the ligand crystal structure itself, resulting in the parallel arrangement of aniline rings, with the centroid distance being $4.46 \AA$. This structure shows the flexible behavior of $\mathrm{L}$. The $\mathrm{CuCl}_{2}$ metal is linked with the two $\mathrm{NH}_{2}$ groups of aniline rings by means of coordination bonds, forming an irregular tetrahedral configuration, with the $\mathrm{Cu}-\mathrm{N}$ bond distance being $2.001 \AA$ and $2.024 \AA$, respectively (Fig. 2). A single closed complex is connected with neighboring ones via $\mathrm{N}-\mathrm{H} \cdots \mathrm{Cl}$ interactions and $\mathrm{C}-\mathrm{H} \cdots \pi$ interactions (C8-H8 ‥ Cg (centroid of ring C0-C6) $3.492 \AA$ between benzene rings, $137.2^{\circ}$ ) expanding in the three crystallographic directions.

\section{2. $\left[\mathrm{Mn}\left(\mathrm{H}_{2} \mathrm{O}\right)_{2} \mathrm{Cl}_{2}(\mathrm{~L})_{2}\right](2)$.}

$\mathrm{X}$-ray crystallography reveals that the composition of $\mathbf{2}$ is [Mn $\left.\left(\mathrm{H}_{2} \mathrm{O}\right)_{2} \mathrm{Cl}_{2}(\mathrm{~L})_{2}\right]$ and crystallizes in the monoclinic space group $\mathrm{C} 2 / \mathrm{c}$. The $\mathrm{Mn}$ (II) sits on an inversion center in an octahedral environment coordinated by two $\mathrm{NH}_{2}$ groups of the aniline moieties, two water molecules and two chloride ligands. Clearly the two chloride ligands and coordinated water molecules prevent the further coordination with the $\mathrm{NH}_{2}$ from the other ligands. A similar coordination environment has been observed using a shorter dianiline ligand [15]. Therefore no polymeric formation results and the coordination complex can be regarded as $0 \mathrm{D}$ (Fig. 3). The uncoordinated $\mathrm{NH}_{2}$ groups of L form hydrogen bonds with the coordinated water in the adjacent complex. The hydrogen bond between the Mn-bound water and $\mathrm{Cl}$ on an adjacent $\mathrm{Mn}$ center further links the chains into a 2D layer structure through $\mathrm{N}-\mathrm{H} \cdots \cdot \pi$ interactions.

\section{3. $\left[\mathrm{Ni}\left(\mathrm{H}_{2} \mathrm{O}\right)_{2}(\mathrm{~L})_{2}\right] \mathrm{Cl}_{2}$ (3) and $\left[\mathrm{Co}\left(\mathrm{H}_{2} \mathrm{O}\right)_{2}\left(\mathrm{~L}_{2}\right] \mathrm{Cl}_{2}\right.$ (4).}

Crystallographic analysis by means of single crystal X-ray diffraction shows that $\mathbf{3}$ and $\mathbf{4}$ are isostructural, with formulas $\left[\mathrm{Ni}\left(\mathrm{H}_{2} \mathrm{O}\right)_{2}(\mathrm{~L})_{2}\right] \mathrm{Cl}_{2}$ and $\left[\mathrm{Co}\left(\mathrm{H}_{2} \mathrm{O}\right)_{2}(\mathrm{~L})_{2}\right] \mathrm{Cl}_{2}$, respectively. Both crystallize in the monoclinic $P 2_{1} / c$ space group and have similar unit cell parameters (see ESI). Herein, crystal $\mathbf{3}$ is used as a representative structure to be described in detail their topological features (Fig. 4). The Ni atom shows octahedral coordination geometry, as it is bound to four equatorial $\mathrm{NH}_{2}$ groups of $\mathbf{L}$

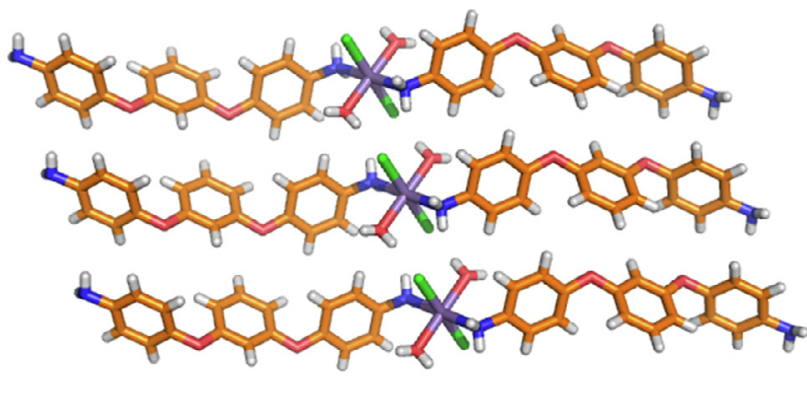
2

Fig. 3. The single crystal X-ray structure of 2 showing how the coordination polymer is not formed but a discrete OD complex. Color code: carbon: orange; nitrogen: blue; oxygen: red; chloride: green; manganese: grey; hydrogen: white. 
(a)

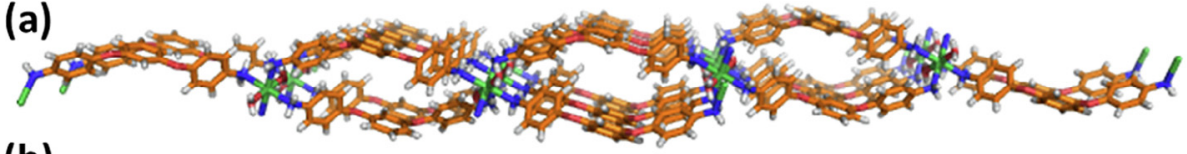

(b)

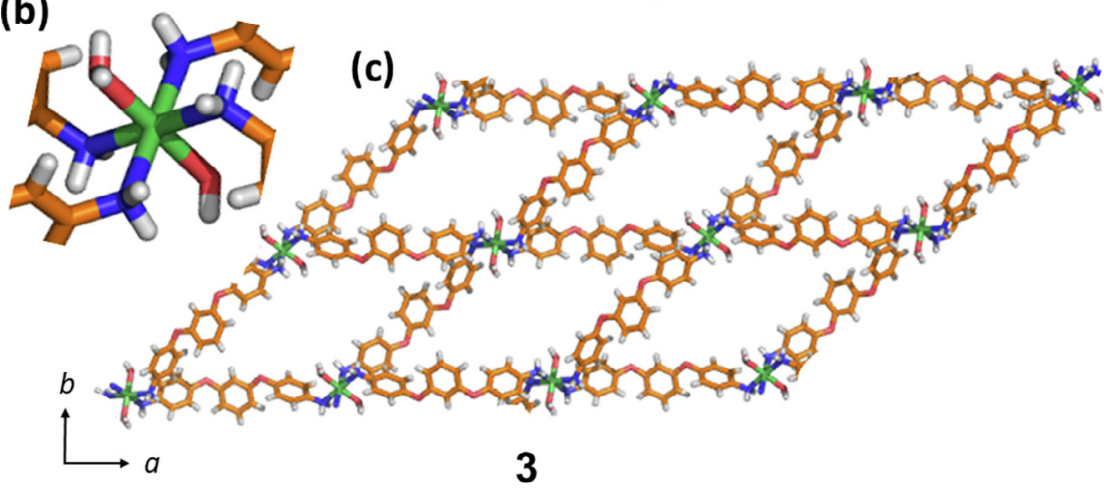

Fig. 4. The crystal structure of 3 showing the polymeric chain viewed approximately along the $b$-axis (a), and coordination geometry around the Ni metal (b). 2D layered structure of viewed along the $c$-axis. The $\mathrm{Cl}^{-}$counter anions balancing the positive charge of the framework are not shown for clarity purposes. Color code: carbon: orange; nitrogen: blue; oxygen: red; nickel: green; hydrogen: white. ligands [Ni-N1: $2.210 \AA$, Ni-N2: $2.155 \AA$ ] and two trans axial water molecules [Ni-O: $2.061 \AA$ A (Fig. 4b). The coordinated water molecules in the $\mathrm{Ni}$ atom causes the chains to be positively charged with the presence of the counter anion $\mathrm{Cl}^{-}$in the crystal lattice. This type of coordination geometry was observed using the shorter 4,4'-methylenedianiline [15]. Interestingly, the in situ observation of apical ligand exchange for a similar coordination environment where the reversible switch from charged to neutral and vice versa was monitored by singlecrystal-to-single crystal reactions [16]. Thus, similar solid-state processes might be possible using $\mathbf{3}$ and $\mathbf{4}$.

Viewed along the $c$-axis the coordination geometry of the Ni results in a 2D grid structure (Fig. 4c). The free chloride anion is uncoordinated but acts as hydrogen bonding acceptor forming two H-bond bridges. One is the $\mathrm{O}-\mathrm{H} \cdots \mathrm{Cl}$ (i. O3- $\mathrm{Cl1}$ : $3.126 \AA$ ) with the coordinated water molecules and the other with the $\mathrm{NH}_{2}$ groups of the ligand $\mathrm{N}-\mathrm{H} \cdots \mathrm{Cl}$ (ii. $\mathrm{N} 2 \cdots \mathrm{Cl} 1: 3.295 \AA$ ), joining the chains into a 2D layer array in such a way the void area of a single $2 \mathrm{D}$ layer is cancelled resulting in a non-porous coordination polymer.

In most CPs/MOFs used for the sensing of nitroaromatics use porous structures where the analytes quench the emission properties of the sensor (CPs) once the pollutants enter the channels [17]. However, the synthesis of porous structures is not always straight forward. Therefore, the design and synthesis of nonporous CPs that can also serve as sensors for nitroaromatics is important. Gas adsorption experiments have been carried out to demonstrate the non-porous nature of 3 . The isotherm corresponds to a non porous structure (Figure S4) and shows the capillary condensation of $\mathrm{N}_{2}$ in the interparticle voids space and not in the pores of the material. The small pore volume value obtained (i.e., $0.044 \mathrm{~cm}^{3} / \mathrm{g}$ ) evidences this fact.

\subsection{Photoluminescence and detection of nitroaromatics}

The presence of an optoelectronically active ligand (L) is important as it can be used to generate photoluminescent hybrid metal-organic materials. Thus, we tested their optical activity by performing fluorescence analysis.

Solid-state fluorescence measurements show that emission maxima of the four crystals are very near: $387 \mathrm{~nm}$ for $1\left(\lambda_{\mathrm{ex}}=246 \mathrm{~nm}\right), 391 \mathrm{~nm}$ for $2\left(\lambda_{\mathrm{ex}}=245 \mathrm{~nm}\right), 400 \mathrm{~nm}$ for $3\left(\lambda_{\mathrm{ex}}=247 \mathrm{~nm}\right)$ and $392 \mathrm{~nm}$ for 4 $\left(\lambda_{\mathrm{ex}}=246 \mathrm{~nm}\right.$ ) (Fig. 5). The emission wavelength shows a blue shift compared with that of pure $\mathbf{L}(375 \mathrm{~nm})\left(\lambda_{\mathrm{ex}}=280 \mathrm{~nm}\right)$, as shown in Figure S5 and Figure S6, which might be attributed from the existence of the $d$-orbital of metal atoms and the $\pi^{*} \rightarrow \pi$ electron transfer from ligand to metal atoms. The observed luminescence of these four metal coordination compounds belongs to the metal perturbation of the ligand luminescence ( $\mathrm{L}^{*}-\mathrm{L}$ type), suggesting the influence of the metal on the fluorescence performance of the ligand $\mathbf{L}$. The measured

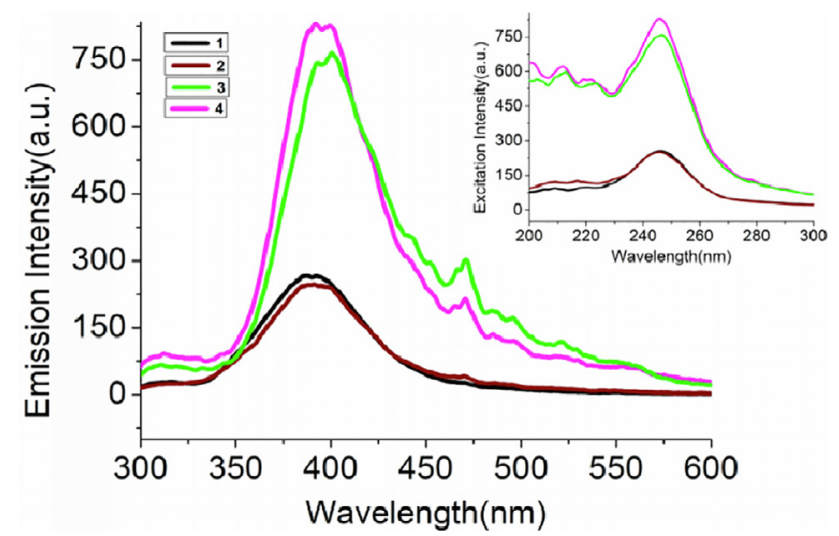

Fig. 5. The solid-state fluorescence emission and excitation spectra of 1-4.

quantum yields $(\Phi)$ for $1-4$ are respectively $6.35 \%, 4.18 \%, 8.88 \%$ and $7.89 \%$. The intensities of the four crystals are significantly different, in which the coordination polymers $\mathbf{3}$ and $\mathbf{4}$ are higher than the compounds 1 and $\mathbf{2}$ due to the different coordination to the metal centers. The quantum yields and the fluorescence intensities are in accordance with the experimental results.

Currently, most reported coordination polymers or MOFs showing potential prospects in the detection of traces amounts of nitroaromatics are focused on Zn, Cd metals [5a,18], however, other metals like Ni or Co have not been much reported up to date [19]. Herein, we have used the nonporous coordination polymer $\mathbf{3}$ as a sensor to detect nitroaromatics compounds, due to the fact that crystals 3 give a better yield than crystal 4 . Therefore, all the results presented in this work have been performed focusing on coordination polymer 3 .

First, organic solvents, including dichloromethane (DCM), dioxane (Diox), diethyl malonate (DM), ethyl acetate (EA), ethanol (EtOH), hexane (He), methanol $(\mathrm{MeOH})$, petroleum ether (PE), 2-butyl alcohol (2BA) and aromatic solvent such as benzene $(\mathrm{PhH})$, have been used to monitor the detection ability of coordination polymer 3 . Microcrystalline $3(7.50 \mathrm{mg})$ were added in acetonitrile $(10 \mathrm{ml})$ to form the suspension $\left(1 \times 10^{-3} \mathrm{~mol} / \mathrm{L}\right)$ where the above-mentioned solvents were added separately $(800 \mathrm{ppm})$. No quenching of 3 upon the addition of these solvents was observed as the PL experiments showed a similar emission intensity around $400 \mathrm{~nm}$ (Fig. 6a). Interestingly, upon the addition of nitroaromatics such as nitrobenzene (NB), 2-nitrotoluene (2-NT) and 3-nitrotoluene (3-NT) the emission of 3, was dramatically quenched (Fig. 6a). The quenching effect can be observed visually by taking digital photographs under UV light as shown in Fig. $6 \mathrm{~b}$ by increasing the amount of NB from a blank sample of pure acetonitrile. 


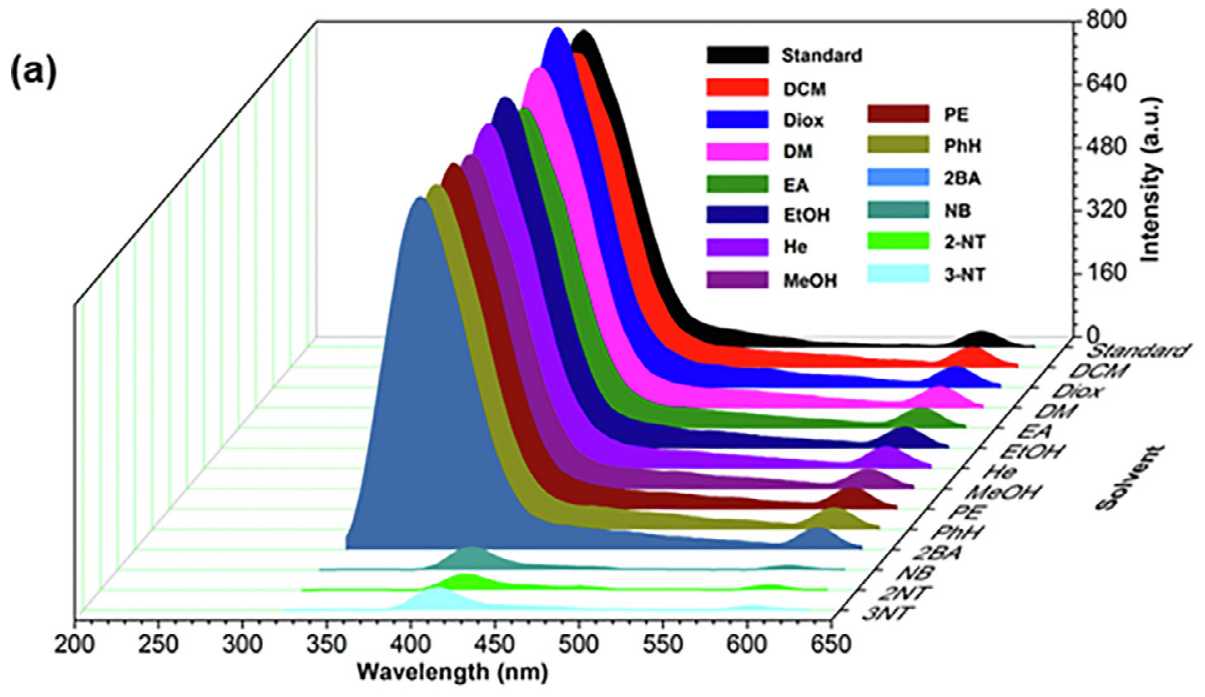

(b)
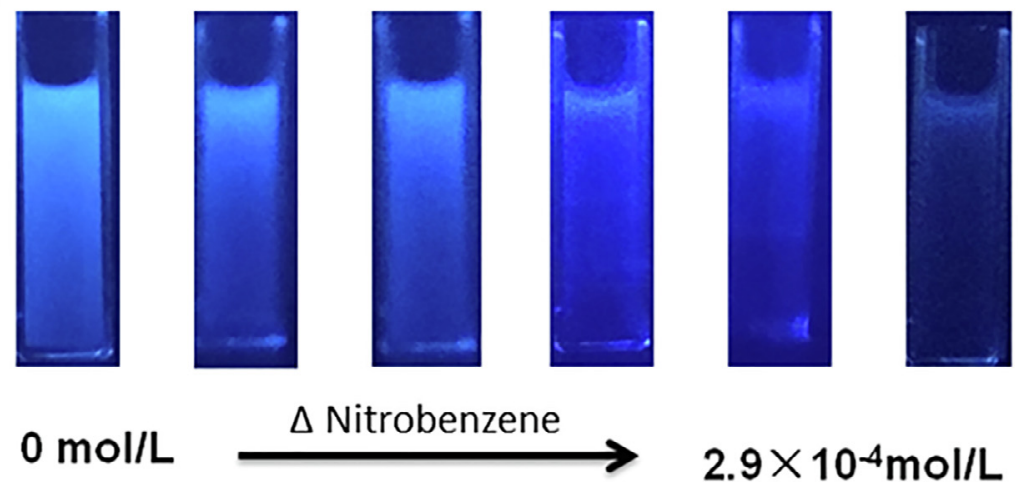

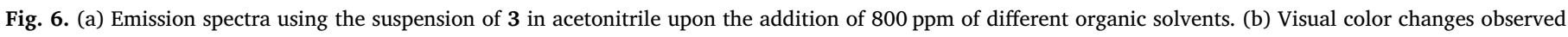
upon subjecting $1 \mathrm{mM}$ solution of crystal 3 in acetonitrile with increasing quantity of NB under UV light.

New experiments aimed at exploring the sensitivity in the nitroaromatic sensing of coordination polymer 3 were carried out using suspensions of 3 in acetonitrile and monitored its PL emission by a progressive increase of the nitroaromatic contents in the suspensions. Fig. 7 clearly shows how the emission intensity decreased upon the gradual addition of nitrobenzene [20]. The Stern-Volmer constant $\left(\mathrm{K}_{\mathrm{SV}}\right)$ constant using 3 as a sensing solid for the detection of nitrobenzene is $2.388 \times 10^{6} \mathrm{M}^{-1}$. The quenching effect by the presence of nitrobenzene at a concentration of $2.9 \times 10^{-4} \mathrm{~mol} / \mathrm{L}$, is evident with a high quenching efficiency of $94.89 \%$ [21]. This shows that coordination polymer 3 can detect nitrobenzene with high sensitivity. According to the IUPAC criteria [22], the limit of detection (LOD) of coordination polymer 3 is $0.62 \mu \mathrm{M}$.

The aromatic detection abilities of coordination polymer 3 have been tested using nitroaromatic derivatives including 2-nitrotoluene (2NT) and 3-nitrotoluene (3-NT). Since coordination polymer 3 is insoluble in acetonitrile, a suspension of 3 in acetonitrile containing 2-NT and 3-NT in different amount were prepared. From the photoluminescent measurements it is observed that the emission intensity diminishes in the presence of nitroaromatic derivatives 2-NT and 3-NT. The emission intensity of $\mathbf{3}$ was also quenched at a concentration of $3.1 \times 10^{-4} \mathrm{~mol} / \mathrm{L}$ for 2-NT, with a quenching efficiency of $95.39 \%$, and $3.0 \times 10^{-4} \mathrm{~mol} / \mathrm{L}$ for 3 -NT, showing a high quenching efficiency of $95.64 \%$, with detection limits of $0.80 \mu \mathrm{M}$ and $0.73 \mu \mathrm{M}$, respectively.

The Stern-Volmer constant $\left(\mathrm{K}_{\mathrm{SV}}\right)$ using 3 as a sensing solid are $1.876 \times 10^{6} \mathrm{M}^{-1}$ and $2.041 \times 10^{6} \mathrm{M}^{-1}$ for 2-NT and 3-NT respectively.

Since Ni complexes are rarely reported in fluorescence detection of nitroaromatics, 3 was compared with reported Cd coordination polymers. The obtained values demonstrate that 3 is more sensitive in comparison to some other sensors (Ksv of $\left\{\left[\mathrm{Cd}_{2}(\mathrm{~L})\right.\right.$ (Dimethylacetamide)] $\left.\cdot \mathrm{H}_{2} \mathrm{~N}(\mathrm{Me})_{2}\right\}_{\mathrm{n}}$ [23]: $4.9 \times 10^{3} \mathrm{M}^{-1}$ and Ksv of $\left.\left[\mathrm{H}_{2} \mathrm{~L}\right]^{2+}\left[\mathrm{CdCl}_{4}\right]^{2-}[24]: 6.09 \times 10^{3} \mathrm{M}^{-1}\right)$. The detection limits are comparable to different sensing methods such as hanging mercury drop electrode (i.e., LOD of: $5 \times 10^{-6} \mathrm{M}$ ) [25]. About the quenching mechanism by nitroaromatics, our conclusion is that complex $\mathbf{3}$ belongs to static quenching according to the linearity of the Stern-Volmer plot and the Ksv value calculated for NB, 2-NB, and 3-NB. The Ksv for static quenching corresponds to the association constant $\mathrm{K}_{\mathrm{A}}[26,27]$.

\subsection{Control experiments using free $L$ for the sensing of nitroaromatics}

The conjugated $\pi$-rich nature of ligand $\mathbf{L}$ due to the interaction with the nitroaromatic compounds in the suspension of 3 results in the quenching of the photoemission. Since free ligand $\mathbf{L}$ is luminescent and $\mathbf{3}$ is also luminescent, further experiments using only ligand $\mathbf{L}$ have been carried out. The experimental results show that the luminescence intensity of a solution in acetonitrile of the free ligand is not as strong as that of the suspension of $\mathbf{3}$ and the quenching effect is not obvious (Fig. 7). The emission intensity of $\mathbf{L}$ was quenched at a concentration of $750 \mathrm{ppm}$ for NB with a quenching efficiency of $85.78 \%, 900 \mathrm{ppm}$ for 2NT, quenching efficiency of $82.93 \%, 800 \mathrm{ppm}$ for 3-NT, quenching efficiency of $84.56 \%$ (Fig. $7 \mathrm{~d}$-f). The Ksv are $2.47 \times 10^{4} \mathrm{M}^{-1}, 2.85 \times 10^{4}$ $\mathrm{M}^{-1}, 2.69 \times 10^{4} \mathrm{M}^{-1}$, respectively (See ESI for further details).

The excited electrons by the photons are transferred to the nitroaromatic derivatives that contain the electron-deficient $-\mathrm{NO}_{2}$ group, 

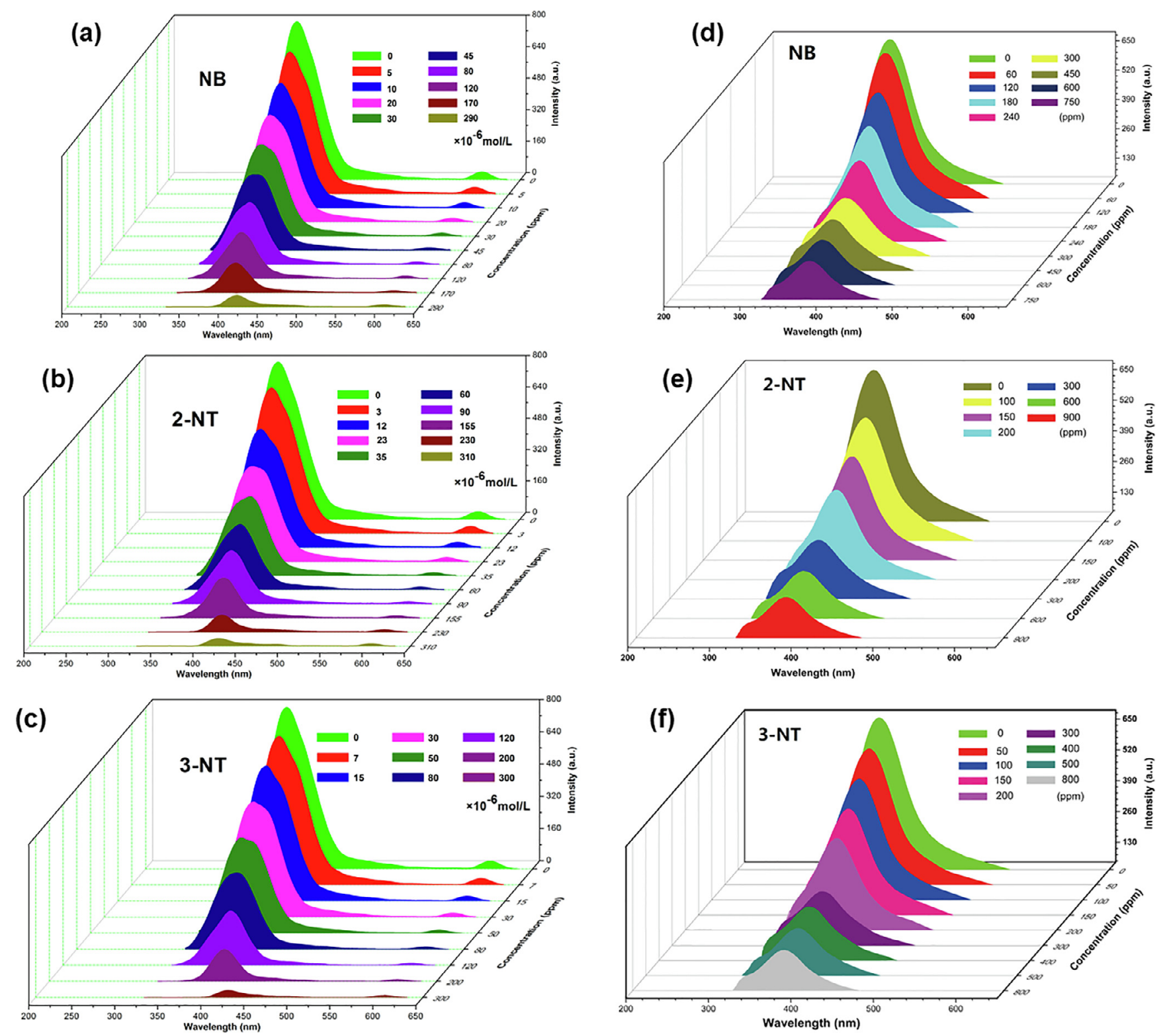

Fig. 7. Fluorescence spectra using suspensions of 3 in acetonitrile: a) NB, b) 2-NT, c) 3-NT. Emission of a solution of $\mathbf{L}$ in acetonitrile $\left.\left(1 \times 10^{-3} \mathrm{~mol} / \mathrm{L}\right) \mathrm{d}\right) \mathrm{NB}$, e) 2-NT and f) 3-NT.

and quenching occurs decreasing the fluorescence intensities of coordination polymer 3. Importantly, using benzene, there is no quenching activity. This can be explained by the absence of the nitroaromatic group. Crucially, 3 does not have problems in detecting large molecules since it is not necessary for the molecules to diffuse into the pores as the quenching occurs in the surface of the material.

The crystalline stability of $\mathbf{3}$ in a suspension of acetonitrile was prepared and then filtered and monitored by XRPD. As shown in Figure S10, there is no change in the structure as observed by the good diffraction displayed by the powders used in the suspension. Additional SEM images clearly showed that $\mathbf{3}$ is a microcrystalline material and that the shape of the solid is maintained after the sensing experiments (see Figure S11). Therefore, $\mathbf{3}$ can be used for further sensing in a recyclable manner.

Moreover, a filtration experiment was carried out in order to understand if the sensing takes place at the surface of $\mathbf{3}$. It was found that the fluorescence intensity of the solution after the filtration of $\mathbf{3}$ was significantly weakened when the suspended particles were filtered out (Figure S12). This experiment indicated that the reaction occurs on the surface of the coordination polymer particles and is not in solution

\section{Conclusions}

In summary, the coordination chemistry of the ligand 4,4'-(1,3phenylenedioxy)-dianiline with metal chlorides resulted in four new supramolecular hybrid metal organic materials. The 2D Ni coordination polymer 3 which can be easily prepared also by LAG (i.e., fast and large amounts), showed a high quenching efficiency towards nitrobenzene (94.89\%), 2-nitrotoluene (95.39\%) and 3-nitrotoluene (95.64\%) detection. The quenching efficiency of $\mathbf{3}$ is better than that of the free ligand $\mathrm{L}$. Therefore, the reported coordination polymer can be used as for the sensing of nitroaromatics. The 0D nature of 2 with two $\mathrm{NH}_{2}$ groups uncoordinated opens up for the possibility to explore the coordination behaviour via mechanochemical means (LAG) or by exploiting solid liquid interface reactions in the presence of different metal centers $[3 e, 28]$. This can lead to new hetero-bimetallic coordination polymers. Further work addressing the structural properties and functional applications of ligand $\mathbf{L}$ with the metal chlorides used in 
this work but using second sphere interactions will be carried out.

\section{Author contributions}

The manuscript was written through contributions of all authors. All authors have given approval to the final version of the manuscript.

\section{Funding sources}

We would like to thank the National Science Foundation of China (No. 21571090) and Lianoning BaiQianWan Talents Program and Lianoning Provincial Department of Education Innovation Team Project (LT2017010) for supporting our research.

\section{Notes}

Any additional relevant notes should be placed here.

\section{Appendix A. Supplementary data}

Supplementary data to this article can be found online at https:// doi.org/10.1016/j.ica.2019.05.012.

\section{References}

[1] (a) G.R. Desiraju, Crystal Engineering: The design of Organic Solids, Elsevier, 1989, Amsterdam.;

(b) L.R. MacGillivray, in Metal-Organic Frameworks: Design and Application, Wiley \& Sons, 2010.

[2] (a) B.F. Hoskins, R. Robson, J. Am. Chem. Soc. 111 (1989) 5962;

(b) M. Fujita, Y.J. Kwon, S. Washizu, K. Ogura, J. Am. Chem. Soc. 116 (1994) 1151

(c) S. Subramanian, M.J. Zaworotko, Angew. Chem., Int. Ed. 34 (1995) 2127;

(d) O.M. Yaghi, H. Li, J. Am. Chem. Soc. 117 (1995) 10401;

(e) M. Kondo, T. Okubo, A. Asami, S.I. Noro, T. Yoshitomi, S. Kitagawa, T. Ishii,

H. Matsuzaka, K. Seki, Angew. Chem., Int. Ed. 38 (1999) 140;

(f) M. Eddaoudi, D.B. Moler, H. Li, B. Chen, T.M. Reineke, M. O'Keeffe, O. M., Yaghi,, Acc. Chem. Res. 34 (2001) 319-330;

(g) J. Martí-Rujas, M. Kawano, Acc. Chem. Res. 46 (2013) 493-505.

[3] (a) E. Barea, C. Montoro, J.A.R. Navarro, Chem. Soc. Rev. 43 (2014) 5419-5430;

(b) B. Li, H.-M. Wen, W. Zhou, B. Chen, J. Phys. Chem. Lett. 5 (2014) 3468-3479;

(c) O.T. Wilcox, A. Fateeva, A.P. Katsoulidis, M.W. Smith, C.A. Stone,

M.J. Rosseinsky, Chem. Commun. 51 (2015) 14989-14991;

(d) J. Martí-Rujas, S. Bonafede, D. Tushi, M. Cametti, Chem. Commun. 51 (2015) 12357-12360;

(e) M. Cametti, J. Martí-Rujas, Dalton Trans. 45 (2016) 18832-18837.

[4] (a) S. Kitagawa, R. Kitaura, S. Noro, Angew. Chem., Int. Ed. 43 (2004) 2334-2375; (b) G. Férey, Chem. Soc. Rev. 37 (2008) 191-214.

[5] (a) L.E. Kreno, K. Leong, O.K. Farha, M. Allendorf, R.P.V. Duyne, J.T. Hupp, Chem. Rev. 112 (2012) 1105;

(b) D. Banerjee, Z. Hu, J. Li, Dalton Trans. 43 (2014) 10668.

[6] (a) A.K. Chaudhari, S.S. Nagarkar, B. Joarder, S.K. Ghosh, Cryst. Growth Des. 13 (2013) 3716;

(b) Y. Rachuri, B. Parmar, K.K. Bisht, E. Suresh, Cryst. Growth Des. 17 (2017) 1363-1372;

(c) Y. Rachuri, B. Parmar, K.K. Bisht, E. Suresh, Dalton Trans. 45 (2016) 7881-7892;

(d) B. Parmar, Y. Rachuri, K.K. Bisht, E. Suresh, Chemistry Select 1 (2016) 6308-6315;

(e) B. Parmar, Y. Rachuri, K.K. Bisht, R. Laiya, E. Suresh, Inorg. Chem. 5 (2017) 2627-2638.

[7] (a) S.J. Loeb, in: Comprehensive Supramolecular Chemistry, ed. J.L. Atwood, J.E. D. Davies, D.D. MacNicol, F. Vögtle, Elsevier Science, New York, 1996, vol. 1, p. 733.

(b) Z. Liu, S.T. Schneebeli, J.F. Stoddart, Chimia 68 (2014) 315-320

(c) J. Martí-Rujas, F. Guo, Dalton Trans. 45 (2016) 13648-13662;

(d) W.-L. Duan, H.-C. Wang, J. Martí-Rujas, F. Guo, CrystEngComm 20 (2018) 323-327; (e) H. Guan, Z. Wang, A. Famulari, X. Wuang, F. Guo, J. Martí-Rujas, Inorg. Chem. 53 (2014) 7438-7445;

(f) H. Li, F. Guo, M. Kou, A. Famulari, Q. Fu, J. Martí-Rujas, Inorg. Chem. 56 (2017) 6584-6590

(g) F. Guo, Z. Wang, J.-J. Zhang, A. Famulari, H.-T. Li, J. Martí-Rujas, Dalton Trans. 46 (2017) 9466-9471

[8] S. Shanmugaraju, S.A. Joshi, P.S. Mukherjee, J. Mater. Chem. 21 (2011) 9130-9138.

[9] (a) F.Y. Zhang, H.L. Xu, Z.M. Su, Org. Electron. 57 (2018) 68-73;

(b) J. Soldevila-Sanmartin, T. Calvet, M. Font-Bardia, C. Domingo, J.A. Ayllon, J. Pons, Dalton Trans. 47 (2018) 6479-6493;

(c) A.M. Fanning, S.E. Plush, T. Gunnlaugsson, Org. Biomol. Chem. 13 (2015) 5804-5816.

[10] (a) L. Li, F. Maddalena, M. Oliveros, M. Caironi, F. Guo, J. Martí-Rujas, CrystEngComm 16 (2014) 10888-10892;

(b) L. Li, J. Tong, F. Guo, J. Martí-Rujas, CrystEngComm 18 (2016) 2284-2288.

[11] D. Cortecchia, C. Soci, M. Cametti, A. Petrozza, J. Martí-Rujas, ChemPlusChem 82 (2017) 681-685.

[12] M. Alexandru, M. Cazacu, A. Vlad, A.M. Macsim, G. Hitruc, D. Ionita, Polym. Plas. Technol. Eng. 50 (2011) 539-546.

[13] (a) N.H. You, C.C. Chueh, C.L. Liu, M. Ueda, Macromolecules 42 (2009) 4456-4463;

(b) C.J. Chen, H.J. Yen, W.C. Chen, G.S. Liou, J. Polym. Sci. Part A: Polym. Chem. 49 (2011) 3709-3718.

[14] (a) T. Friščić, A.V. Trask, W. Jones, W.D.S. Motherwell, Angew. Chem., Int. Ed. 45 (2006) 7546-7550;

(b) D. Braga, S.L. Giaffreda, F. Grepioni, M.R. Chierotti, R. Gobetto, G. Palladino, M. Polito, CrystEngComm 9 (2007) 879-881;

(c) T. Friščić, A.V. Trask, W.D.S. Motherwell, W. Jones, Cryst. Growth Des. 8 (2008) 1605-1609.

[15] L. Carlucci, G. Ciani, D.M. Proserpio, F. Porta, CrystEngComm 8 (2006) 696-706.

[16] (a) K. Takaoka, M. Kawano, M. Tominaga, M. Fujita, Angew. Chem. Int. Ed. 44 (2005) 215112145

(b) K. Takaoka, M. Kawano, T. Hozumi, S.I. Ohkoshi, M. Fujita, Inorg. Chem. 45 (2006) 3976-3982.

[17] (a) A. Lan, K. Li, H. Wu, D.H. Olson, T.J. Emge, W. Ki, M. Hong, J. Li, Angew. Chem. Int. Ed. 48 (2009) 2334-2338;

(b) A. Santra, M. Francis, S. Parshamoni, S. Konar, Chemistry Select 2 (2017) 3200-3206;

(c) D. Yan, Y. Tang, H. Lin, D. Wang, Scientific Reports 4 (2014) 4337.

[18] (a) Y. Yang, P.J. Du, F. Ma, W.Q. Kan, B. Liu, J. Yang, Cryst. Growth Des. 11 (2011) 5540-5553;

(b) L. Wen, Z. Lu, J. Lin, Z. Tian, H. Zhu, Q. Meng, Cryst. Growth Des. 7 (2007) 93-99.

[19] (a) K.P. Tapan, C. Nabanita, K.B. Parimal, Inorg. Chem. 55 (2016) 1741-1747; (b) R.X. Yao, X. Cui, X.X. Jia, F.Q. Zhang, X.M. Zhang, Inorg. Chem. 55 (2016) 9270-9275;

(c) G.Y. Wang, L.L. Yang, Y. Li, H. Song, W.J. Ruan, Z. Chang, X.H. Bu, Dalton Trans. 42 (2013) 12865-12868.

[20] The luminescence titration results can be treated with the Stern-Volmer equation, $\mathrm{F}_{0} / \mathrm{F}=1+\mathrm{Ksv}[\mathrm{Q}]$, where Ksv is the quenching constant, and $\mathrm{Q}$ is the quencher. In order to determine the quenching efficiencies of the analytes by the sensing solids the Stern-Volmer equation is $F_{0} / F=\left(1+K_{A}[Q]\right)\left(1+k_{0} \tau_{0}[Q]\right)$ is used. Where $F_{0}$ is the emission intensity without the quencher and $\mathrm{F}$ is the intensity of the emission of the indicator that depends on the concentration of the quencher [Q]. Static quenching is determined by the binding of the analite to the indicator and is characterized by the association constant $\mathrm{K}_{\mathrm{A}}$. While collisional quenching depends on the intrinsic fluorescence lifetime $\left(\tau_{0}\right)$ and the rate of analyte-collision $\mathrm{k}_{0}$. Usually, the quenching efficiency Ksv is reported where Ksv corresponds either to $\mathrm{K}_{\mathrm{A}}$ or $\mathrm{k}_{0} \tau_{0}$. See ESI for further information.

[21] Quenching efficiency $=\left(1-\mathrm{F} / \mathrm{F}_{0}\right) \times 100 \%, \mathrm{~F}_{0}$ and $\mathrm{F}$ are the fluorescence intensities before and after the addition of analytes, respectively.

[22] IUPAC criteria for the limit of detection (LOD) is the ratio: $3 \delta / \mathrm{S}$ (where $\delta$ is the standard deviation of the fluorescence intensity before adding the quenchers and $\mathrm{S}$ is the slope of the fitted curve on the Stern-Volmer plot). See ESI for further information.

[23] Y.T. Yan, J. Liu, G.P. Yang, F. Zhang, Y.K. Fan, W.Y. Zhang, Y.Y. Wang, CrystEngComm 20 (2018) 477-486.

[24] W.L. Duan, H.C. Wang, Marti-Rujas, J.F. Guo, CrystEngComm. 20 (2018) 323-327.

[25] S.X. Liang, H.K. Zhang, D. Lu, Environ. Monit. Assess. 129 (2007) 331-337.

[26] L.L. Zhou, M. Li, H.Y. Lu, C.F. Chen, Polym. Chem. 7 (2016) 310-318.

[27] M.E. Germain, M.J. Knapp, Chem. Soc. Rev. 38 (2009) 2543-2555.

[28] J. Martí-Rujas, Y. Matsushita, F. Izumi, M. Fujita, M. Kawano, Chem. Commun. 46 (2010) 6515-6517. 